Cite this: Phys. Chem. Chem. Phys., 2011, 13, 13920-13925

\title{
Core-shell effects in the ionization of doped helium nanodroplets
}

\author{
Jun Liu, Benjamin Shepperson, Andrew M. Ellis and Shengfu Yang* \\ Received 7th March 2011, Accepted 26th April 2011 \\ DOI: $10.1039 / \mathrm{c} 1 \mathrm{cp} 20653 \mathrm{~b}$
}

Core-shell particles with water clusters as the core and surrounded by an atomic or molecular shell have been synthesized for the first time by adding water and a co-dopant sequentially to helium nanodroplets. The co-dopants chosen for investigation were $\mathrm{Ar}, \mathrm{O}_{2}, \mathrm{~N}_{2}, \mathrm{CO}, \mathrm{CO}_{2}, \mathrm{NO}$ and $\mathrm{C}_{6} \mathrm{D}_{6}$. These co-dopants have been used to investigate the effect of an outer shell on the ionization of the core material by charge transfer in helium nanodroplets. The specific aim was to determine how the identity of the shell material affects the fragmentation of water cluster ions, i.e. whether it helps to stabilize parent ion $\left(\left(\mathrm{H}_{2} \mathrm{O}\right)_{n}{ }^{+}\right)$formation or increases fragmentation (to form $\left.\left(\mathrm{H}_{2} \mathrm{O}\right)_{n} \mathrm{H}^{+}\right) . \mathrm{N}_{2}, \mathrm{O}_{2}, \mathrm{CO}_{2}$ and $\mathrm{C}_{6} \mathrm{D}_{6}$ all show a marked softening effect, which is consistent with the formation of a protective shell around the water cluster core. For $\mathrm{CO}$ and NO co-dopants, the response is complicated by secondary reactions which actually favour water cluster ion fragmentation for some water cluster sizes.

\section{Introduction}

Helium droplets provide an unusual, nanoscale environment for exploring phenomena at very low temperatures. Typically consisting of $10^{3}-10^{6}$ helium atoms, they can be doped with atoms or molecules, which are then cooled to the equilibrium temperature of the droplets $(0.37 \mathrm{~K}) .{ }^{1}$ Through spectroscopic investigation, the dopants can act as probes of the surrounding superfluid environment. ${ }^{2-4}$ Equally, the liquid helium can provide a medium for forming and characterising new types of atomic and molecular aggregates, including molecular clusters organised in metastable configurations. ${ }^{5-8}$

Although the ionization of a single dopant species in helium droplets is quite well studied, the ionization and subsequent chemistry of mixed dopants has attracted much less attention. This is somewhat surprising given the potential that helium droplets offer for studying ion-molecule reactions at very low temperature. The first specific attempt to study ion-molecule reactions in helium droplets involving two different molecular constituents was carried out by Fárnik and Toennies, who characterized the reactions $\mathrm{N}_{2}^{+}+\mathrm{D}_{2}, \mathrm{CH}_{4}{ }^{+}+\mathrm{D}_{2}$, and $\mathrm{CH}_{3}{ }^{+}+\mathrm{D}_{2} .{ }^{9}$ These reactions were initiated by primary electron impact ionization of the doubly doped droplets and both reaction end-products and some reaction intermediates were identified.

More recently, Denifl and co-workers have presented a preliminary account of the ion-induced chemistry between water clusters and $\mathrm{C}_{60}$ in helium droplets, leading to the observation of $\mathrm{C}_{60}\left(\mathrm{H}_{2} \mathrm{O}\right)_{n}{ }^{+}$adducts, as well as dehydrogenated cluster ions of

Department of Chemistry, University of Leicester, University Road, Leicester, LE17RH,UK.E-mail: sfy1@le.ac.uk;

Fax: + 44 (0)116 252 3789; Tel: +44 (0)116252 2127 the type $\mathrm{C}_{60}\left(\mathrm{H}_{2} \mathrm{O}\right)_{n} \mathrm{OH}^{+} .{ }^{10}$ The formation of the latter ions was attributed to reactions involving the doubly charged cation, $\mathrm{C}_{60}{ }^{2+}$. With a slightly different emphasis, Ren and Kresin have co-embedded water molecules with fragile organic molecules in helium droplets and have shown that small water clusters can have a major effect in softening the ionization process, thus drastically reducing the degree of fragmentation of the organic ions. ${ }^{11}$ Crucially, this softening effect was found to operate only for those organic molecules with low or zero dipole moments, which then allow the positive hole to be preferentially steered towards the water. The initial acceptance of the positive charge by the water must allow some dissipation of excess energy prior to charge transfer onto the organic molecule.

In this work we have embarked on an investigation of the response of mixed molecule systems to electron impact ionization. Our particular aim here is to use the helium droplets to form a core-shell structure for the two-component mixture, and then see how this affects the subsequent ionmolecule chemistry. Helium nanodroplets are unique in this regard in that well-defined core-shell structures should be possible to form by sequential pickup of different types of molecules because of the rapid cooling by the surrounding helium and the very low ultimate temperature attainable. The only previous attempt to explore a comparable core-shell effect in helium nanodroplets was reported by Lewis et al. ${ }^{12}$ In their study Lewis and co-workers coated a triphenylmethanol (TPM) monomer with neon atoms and saw a clear reduction in the fragmentation of the parent ion as more neon was added. This was interpreted as a softening effect caused by the formation of a protective shell around the TPM and in fact the number of atoms in the first shell $(\sim 20 \mathrm{Ne}$ atoms $)$ could be inferred from the response of the parent ion to the mean number of neon atoms picked up by the droplets. To date, 
no one has explored the effect of core-shell formation on two species capable of chemically interacting in helium nanodroplets.

In the present work water clusters were chosen as one of the reactive species because their corresponding cations are well studied. $\left(\mathrm{H}_{2} \mathrm{O}\right)_{n}{ }^{+}(n=2,3,4 \ldots)$ ions are known to have large structural differences from the corresponding neutral water clusters and the cations are therefore unstable because they are formed in highly vibrationally excited states by vertical ionization. ${ }^{13}$ Consequently, in gas-phase ionization experiments, only protonated ions, $\left(\mathrm{H}_{2} \mathrm{O}\right)_{n} \mathrm{H}^{+}$, can be observed because $\mathrm{OH}$ loss is facile. Unprotonated water cluster ions can be formed only when extra bodies are present which can rapidly remove some of the excess vibrational energy in the parent ions. The more effective the quenching, the more water parent ions will be produced. Thus, $\left(\mathrm{H}_{2} \mathrm{O}\right)_{n}{ }^{+}$ions have been seen in the gas phase when formed by electron impact of $\operatorname{Ar}_{m}\left(\mathrm{H}_{2} \mathrm{O}\right)_{n}$ clusters, since the argon is able to provide sufficiently fast quenching to allow some $\left(\mathrm{H}_{2} \mathrm{O}\right)_{n}{ }^{+}$ions to survive. ${ }^{14}$ Helium nanodroplets can perform an equivalent task, although water cluster ion fragmentation is still the dominant product channel. ${ }^{15,16}$ Consequently, water cluster ions provide a useful measure of the effect of a co-dopant shell on a water cluster because (i) there is a clear fragmentation channel, (ii) that channel is not fully quenched by the helium acting alone, and (iii) the unprotonated channel is likely to increase in importance if additional quenching is provided.

In this work we have combined water clusters with a variety of co-dopants, namely $\mathrm{Ar}, \mathrm{O}_{2}, \mathrm{~N}_{2}, \mathrm{CO}, \mathrm{NO}, \mathrm{CO}_{2}$, and $\mathrm{C}_{6} \mathrm{D}_{6}$. These molecules were chosen so as to span the range from monatomic through to polyatomic species, and to access a range of ionization energies, with some lying above that of water and others below. We observe a genuine softening effect for the ionization of water clusters for most co-dopants. Furthermore, the role of core-shell structures is established through reversal of the order of addition of the two dopants.

\section{Experimental}

The experimental apparatus has been fully described previously. ${ }^{17}$ Briefly, the apparatus consists of a pulsed helium droplet source, a series of pick-up cells, and an electron impact ionization reflectron time-of-flight mass spectrometer (TOF-MS). The energy of electron impact was maintained at $100 \mathrm{eV}$ throughout this study. The pulsed source consists of a solenoid valve (General Valve series 99) with a Kel-F poppet and a home-made faceplate, which is cooled by a closed-cycle cryostat. For all of the experiments in this work, the stagnation pressure was fixed at 20 bar and the nozzle temperature was $15 \mathrm{~K}$, giving helium droplets of estimated mean size $\langle N\rangle=$ 7500 helium atoms. ${ }^{17}$

The droplets leaving the nozzle were skimmed and then enter two consecutive pick-up cells mounted in the pickup chamber with an aperture of $6 \mathrm{~mm}$ diameter, where dopants can be added. In most cases, water vapour was supplied at a fixed partial pressure in the first pick-up cell, with an average pickup of about 3 water molecules. In the mass spectrum water cluster ions containing up to 15 water molecules can be observed, which is as expected given that the pickup process is statistical. The co-dopant, chosen from one of $\mathrm{Ar}, \mathrm{N}_{2}, \mathrm{O}_{2}$,
$\mathrm{NO}, \mathrm{CO}, \mathrm{CO}_{2}$ and $\mathrm{C}_{6} \mathrm{D}_{6}$, was added to the second pick-up cell. The partial pressure inside the pickup cells is several hundred times higher than outside and it is difficult to measure the pressure using the ion gauge directly. As an alternative method for determining the relative quantities of dopants, we have used their parent ion signals obtained when the gating of the TOF-MS signal output was shifted by $1 \mathrm{~ms}$, such that no helium droplets remain.

Adding water to the first pickup cell ensures that water clusters form prior to the addition of a second species, so if a core-shell structure is formed it will have a water core and a co-dopant shell. Reversal of the pickup order should produce a co-dopant core with a partially or fully formed water shell around it. Alternatively, it is possible in both cases that a core-shell structure is not formed, and that we therefore have individual clusters of water and the co-dopant which are linked together by some means. If the latter occurs, then we should see the same response in the mass spectrum regardless of the order of pickup because water clusters will aggregate anyway due to the dipole moment of water and the possibility of hydrogen bonding. However, if core-shell structures form we would expect the pickup order to be important. To verify that a core-shell structure is formed with water as the core, we also performed an experiment with $\mathrm{O}_{2}$ in the first pickup cell and water in the second pickup cell. In addition, we also carried out experiments where water was supplied in the first pickup cell at a constant pressure and the $\mathrm{O}_{2}$ partial pressure was varied in order to estimate how many $\mathrm{O}_{2}$ molecules would be required to form a closed shell.

For most of the co-dopants the partial pressures added gave co-dopant $/ \mathrm{H}_{2} \mathrm{O}$ ratios up to 40 . Given the observation by Lewis et al. ${ }^{12}$ that 10 neon atoms are sufficient to form the first shell around a relatively large TPM molecule, we would expect that small water clusters can be fully immersed in the co-dopants at this high ratio.

For $\mathrm{C}_{6} \mathrm{D}_{6}$, the highest partial pressure applied was similar to that of the water vapour. When more benzene molecules are added, benzene cluster ions become the prominent feature in the mass spectrum while water cluster ions disappear, presumably because benzene has a much lower ionization energy than water and therefore charge resides exclusively on the benzene. The amount of benzene added would not be sufficient to form a closed shell around the water cluster core, but given that benzene is much larger than the other co-dopants, and its ionization cross section is about 10 times larger than water at low electron impact energy, ${ }^{24}$ we still expect that benzene will have a shielding effect similar to the formation of a partial shell around the water cluster core.

\section{Results}

In mass spectra of helium droplets doped with water only, the major peaks are derived from protonated water cluster ions, $\left(\mathrm{H}_{2} \mathrm{O}\right)_{n} \mathrm{H}^{+}$, with the $\left(\mathrm{H}_{2} \mathrm{O}\right)_{n}{ }^{+}$signal being considerably weaker. As will be seen below, this trend is maintained when a co-dopant is added to the water clusters. However, the protonated/unprotonated signal ratio may be altered at the quantitative level by the co-dopants. Furthermore, binary cluster ions composed of both dopants are also observed. 


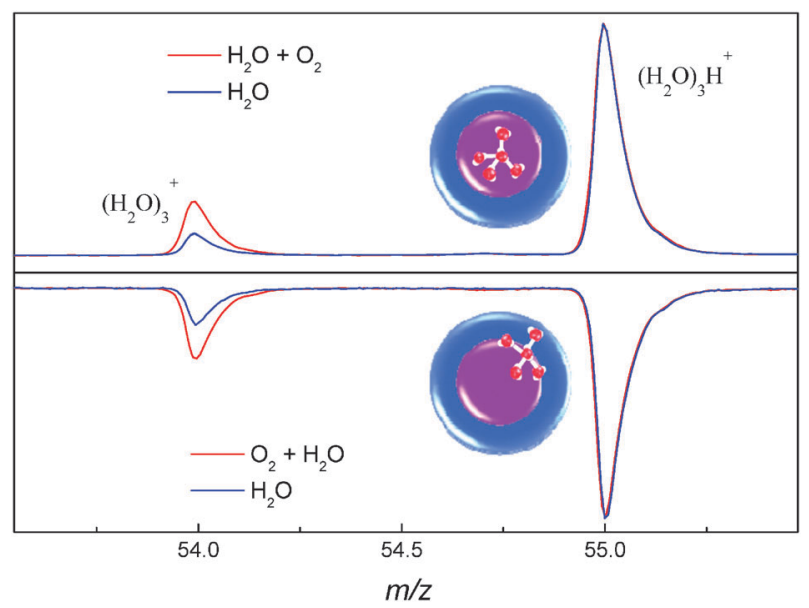

Fig. 1 Comparison of the yields of $\left(\mathrm{H}_{2} \mathrm{O}\right)_{3}{ }^{+}$relative to $\left(\mathrm{H}_{2} \mathrm{O}\right)_{3} \mathrm{H}^{+}$for different pickup orders of $\mathrm{H}_{2} \mathrm{O}$ and $\mathrm{O}_{2}$. The red line in the upper plot is for addition of $\mathrm{H}_{2} \mathrm{O}$ in the first pickup cell and $\mathrm{O}_{2}$ in the second, while the reverse pickup order applies for the red plot in the lower half. The blue lines are for water addition only.

In this work we will concentrate primarily on the bare water cluster ion products.

Owing to the exceptionally high cooling capability of helium droplets, the excess energy of molecules can be dissipated almost instantly when they are picked up by helium droplets. Consequently, addition of different molecules to consecutive pick-up shells ought to lead to the formation of core-shell particles, providing a sufficient quantity of the shell material is added. Evidence that core-shell particles are formed in the current work is provided in Fig. 1. This shows mass spectral data in the region of the $\left(\mathrm{H}_{2} \mathrm{O}\right)_{3}{ }^{+}$ion signal derived when (i) water was added to the first pickup cell and oxygen was added to the second and (ii) when the reverse pickup order was employed. Spectra are shown in the region of the $\left(\mathrm{H}_{2} \mathrm{O}\right)_{3}{ }^{+}$ion because the signal from this ion does not overlap with signal from helium cluster ions, $\mathrm{He}_{n}{ }^{+}$. All plots are normalized for easy comparison such that the $\left(\mathrm{H}_{2} \mathrm{O}\right)_{3} \mathrm{H}^{+}$peaks have the same intensity.

Fig. 1 reveals that, regardless of the order of addition, $\mathrm{O}_{2}$ doping leads to enhanced $\left(\mathrm{H}_{2} \mathrm{O}\right)_{3}{ }^{+}$production relative to $\left(\mathrm{H}_{2} \mathrm{O}\right)_{3} \mathrm{H}^{+}$when compared with the mass spectrum derived from bare water clusters in helium nanodroplets (also shown in Fig. 1). However, when $\mathrm{O}_{2}$ is added to the first pickup cell the enhancement factor for $\left(\mathrm{H}_{2} \mathrm{O}\right)_{3}{ }^{+}$is 2.49 , while for the reversed addition sequence the enhancement factor is 1.92 . On the basis of the observed signal/noise ratios, the precision on the enhancement factors is approximately $\pm 1 \%$. No difference in behaviour would be expected for a homogeneous distribution of $\mathrm{H}_{2} \mathrm{O}$ and $\mathrm{O}_{2}$ and therefore the dependence of the ion signals on the pickup order is clear evidence that distinct structures form, depending on the order of pickup of the dopants. We take this to be evidence of core-shell particle formation.

In a study of triphenylmethanol (TPM) in helium nanodroplets, Lewis et al. ${ }^{12}$ explored the fragmentation of the TPM ion on electron impact ionization of the doped helium droplet. Of particular relevance to this study was an investigation of the effect of added neon atoms on the fragmentation process.

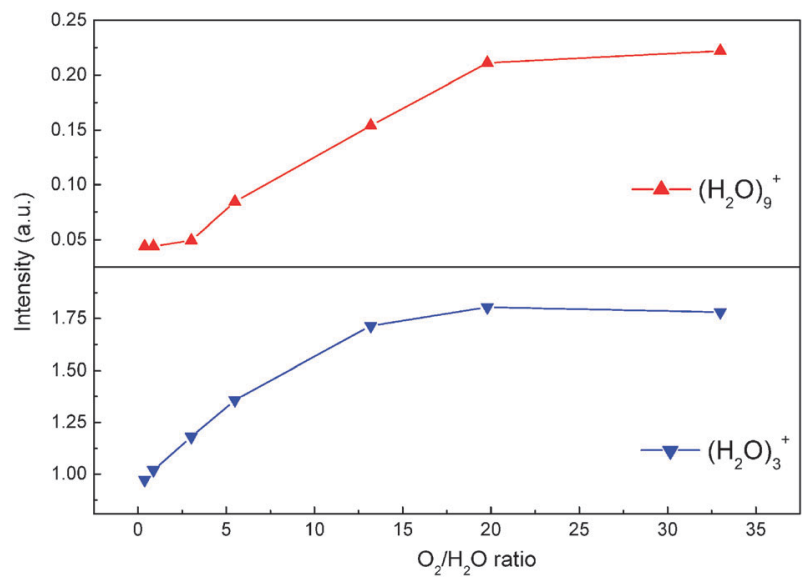

Fig. 2 The dependence of unprotonated water cluster ion intensities on the added amount of $\mathrm{O}_{2}$.

An asymptotic limit in a plot of fractional abundance of TPM parent ion signal was found as a function of the average number of neon atoms added to helium droplets. This limit, which was reached after the addition of roughly 20 neon atoms, was taken to indicate the formation of a complete shell of neon atoms around a TPM molecule. The rationale here is that, after forming this shell, further addition of neon atoms would have a reduced quenching effect on the ion fragmentation process because the additional neon atoms reside in a second shell, where they will bind more weakly and therefore can remove less energy by evaporative loss.

To see if similar behaviour is observed for the core-shell clusters explored in the current work, we take the $\mathrm{O}_{2} / \mathrm{H}_{2} \mathrm{O}$ system as an example. A plot of $\left(\mathrm{H}_{2} \mathrm{O}\right)_{n}{ }^{+}$signal versus the added $\mathrm{O}_{2} / \mathrm{H}_{2} \mathrm{O}$ ratio is shown in Fig. 2. Focusing on $\left(\mathrm{H}_{2} \mathrm{O}\right)_{3}{ }^{+}$ and $\left(\mathrm{H}_{2} \mathrm{O}\right)_{9}{ }^{+}$, the primary findings are: (a) at low pressure, the $\left(\mathrm{H}_{2} \mathrm{O}\right)_{3}{ }^{+}$intensity increases approximately linearly with the amount of $\mathrm{O}_{2}$, while there is little change for $\left(\mathrm{H}_{2} \mathrm{O}\right)_{9}{ }^{+}$when the $\mathrm{O}_{2} / \mathrm{H}_{2} \mathrm{O}$ ratio is $<3$. (b) At high pressure, an asymptotic limit is reached, for $\left(\mathrm{H}_{2} \mathrm{O}\right)_{3}{ }^{+}$at a ratio of $\mathrm{O}_{2} / \mathrm{H}_{2} \mathrm{O}=15$ and for $\left(\mathrm{H}_{2} \mathrm{O}\right)_{9}{ }^{+}$at a ratio of 20 . These differences reflect the fact that: (1) the impact of a co-dopant will be largest for small water clusters and will be less important for larger water clusters; (2) less co-dopant is required to fill the first shell for smaller clusters and more will be needed for larger clusters. The data summarized in Fig. 2 suggests that about $45 \mathrm{O}_{2}$ molecules are necessary to complete the first shell for water trimer while the nonamer requires somewhere in the region of $60 \mathrm{O}_{2}$ molecules.

The impact of other co-dopants on the formation of bare water cluster ions (i.e. without attached co-dopant) is illustrated by the mass spectra shown in Fig. 3. This compares $\mathrm{O}_{2}$ data, seen previously in Fig. 1, with the corresponding findings for Ar and CO. The co-dopants in all three cases were added to the second pickup cell to form a shell around the water core. As in Fig. 1, mass spectra are shown in the region of the $\left(\mathrm{H}_{2} \mathrm{O}\right)_{3}{ }^{+}$ion and the plots are normalized such that the $\left(\mathrm{H}_{2} \mathrm{O}\right)_{3} \mathrm{H}^{+}$peaks are of the same intensity. We can therefore readily compare the $\left(\mathrm{H}_{2} \mathrm{O}\right)_{3}{ }^{+} /\left(\mathrm{H}_{2} \mathrm{O}\right)_{3} \mathrm{H}^{+}$intensity ratios, which we will use as markers for softened ionization. Addition of $\mathrm{O}_{2}$ has a substantial effect on the branching ratio, leading to 


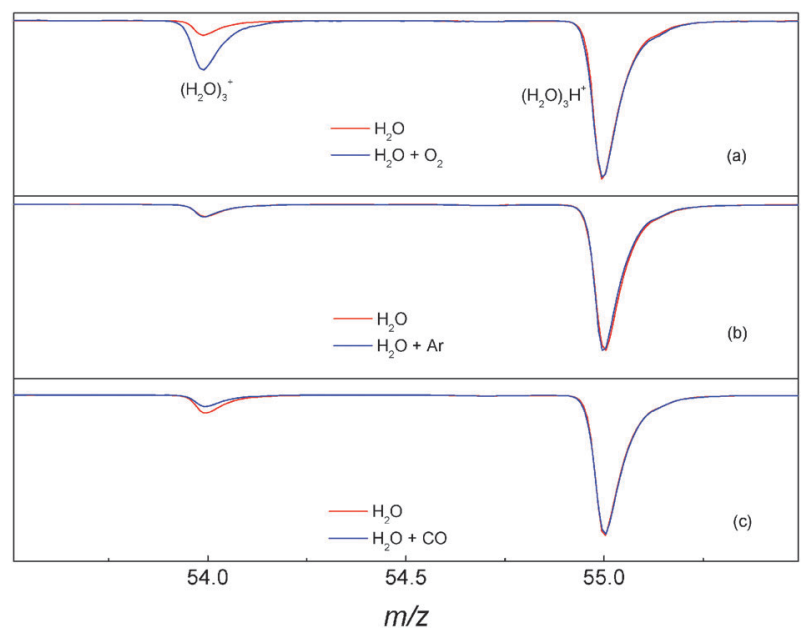

Fig. 3 Comparison of mass spectra in the $\left(\mathrm{H}_{2} \mathrm{O}\right)_{3}{ }^{+}$region for addition of co-dopants (a) $\mathrm{O}_{2}$, (b) $\mathrm{Ar}$ and (c) $\mathrm{CO}$. In each case spectra obtained without a co-dopant are also shown and the co-dopant spectrum is normalized such that the $\left(\mathrm{H}_{2} \mathrm{O}\right)_{3} \mathrm{H}^{+}$peak has the same intensity both with and without the co-dopant.

a much higher proportion of $\left(\mathrm{H}_{2} \mathrm{O}\right)_{3}{ }^{+}$ions relative to $\left(\mathrm{H}_{2} \mathrm{O}\right)_{3} \mathrm{H}^{+}$. However, $\mathrm{CO}$ has the opposite effect, although the impact is not as pronounced as for $\mathrm{O}_{2}$, while the addition of Ar has no detectable effect at all.

A more general way to illustrate the effect of an added species on water cluster ion formation is to directly compare the total ion signals containing $n$ water molecules, i.e., the sum of $\left(\mathrm{H}_{2} \mathrm{O}\right)_{n}{ }^{+},\left(\mathrm{H}_{2} \mathrm{O}\right)_{n-1} \mathrm{H}^{+}, \mathrm{X}_{m}\left(\mathrm{H}_{2} \mathrm{O}\right)_{n}{ }^{+}$and $\mathrm{X}_{m}\left(\mathrm{H}_{2} \mathrm{O}\right)_{n-1} \mathrm{H}^{+}$ signals for a given $n$ in the presence and absence of dopant $\mathrm{X}$. Such a comparison, expressed as a ratio of the total ion signals in the presence and absence of dopant, is presented in Fig. 4 using the $\mathrm{O}_{2} / \mathrm{H}_{2} \mathrm{O}$ and $\mathrm{CO} / \mathrm{H}_{2} \mathrm{O}$ systems as examples. The ratio is plotted on the vertical axis against water cluster size on the horizontal axis in order to show the effect of the co-dopants on water clusters in comparison with bare water clusters in helium

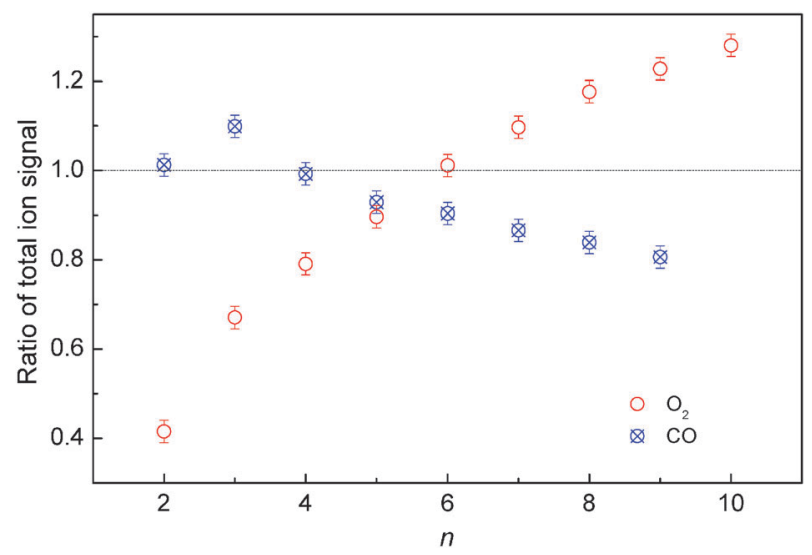

Fig. 4 The ratio of total water cluster ion signals between binary clusters and un-doped water clusters. $(\mathrm{O}) \mathrm{O}_{2}$ added; $(\otimes) \mathrm{CO}$ added. For binary clusters, the total signal includes $\left(\mathrm{H}_{2} \mathrm{O}\right)_{n}{ }^{+},\left(\mathrm{H}_{2} \mathrm{O}\right)_{n-1} \mathrm{H}^{+}$ $\mathrm{O}_{2}{ }^{+}\left(\mathrm{H}_{2} \mathrm{O}\right)_{n}$ and $\mathrm{O}_{2}{ }^{+}\left(\mathrm{H}_{2} \mathrm{O}\right)_{n-1} \mathrm{H}$; for un-doped water clusters, the total signal includes $\left(\mathrm{H}_{2} \mathrm{O}\right)_{n}{ }^{+}$and $\left(\mathrm{H}_{2} \mathrm{O}\right)_{n-1} \mathrm{H}^{+}$for each $n$. The error margins shown are estimates based on the signal-to-noise ratios for the various ion signals. droplets. The ratio increases monotonically with water cluster size for $\mathrm{O}_{2}$, while the trend is opposite for CO.

Since the co-dopant affects the branching ratio between $\left(\mathrm{H}_{2} \mathrm{O}\right)_{n}{ }^{+}$and $\left(\mathrm{H}_{2} \mathrm{O}\right)_{n-1} \mathrm{H}^{+}$, if the unprotonated channel increases in importance relative to the protonated channel then the co-dopant must reduce the tendency for water clusters to fragment, and thus provides a softening effect. In order to quantify this effect we define a parameter, $R_{n}$, as follows:

$$
R_{n}=\frac{\left[\left(\mathrm{H}_{2} \mathrm{O}\right)_{n}^{+} /\left(\mathrm{H}_{2} \mathrm{O}\right)_{n-1} \mathrm{H}^{+}\right]_{\mathrm{X} \cdot \mathrm{H}_{2} \mathrm{O}}}{\left[\left(\mathrm{H}_{2} \mathrm{O}\right)_{n}^{+} /\left(\mathrm{H}_{2} \mathrm{O}\right)_{n-1} \mathrm{H}^{+}\right]_{\mathrm{H}_{2} \mathrm{O}}}
$$

Effectively, when $R_{n}>1$ the ratio $\left[\left(\mathrm{H}_{2} \mathrm{O}\right)_{n}{ }^{+}\right] /\left[\left(\mathrm{H}_{2} \mathrm{O}\right)_{n-1} \mathrm{H}^{+}\right]$ increases when the co-dopant is added to water, and vice versa for $R_{n}<1$. $R_{n}=1$ implies no softening effect of the co-dopant.

For the dopants $\mathrm{O}_{2}, \mathrm{CO}_{2}, \mathrm{~N}_{2}$ and $\mathrm{C}_{6} \mathrm{D}_{6}$, there is a sizeable increase in the unprotonated water cluster ion signals when compared with the protonated channels, and $R_{n}>1$ holds for all $n$ values (as an example see Fig. 5 for $\mathrm{O}_{2} / \mathrm{H}_{2} \mathrm{O}$ clusters). Consequently, there is a marked softening effect by the aforementioned co-dopants. Argon has a negligible effect, whereas for both $\mathrm{CO}$ and $\mathrm{NO}$, the effect of the co-dopant is more complicated. The overall softening effect of $\mathrm{CO}$ and $\mathrm{NO}$ is much less than that of $\mathrm{O}_{2}$. For $\mathrm{O}_{2} R_{n}$ is generally 5-6, whereas $R_{n}$ varies from 0.5 to 2 for $\mathrm{CO}$ and NO. In particular, at some cluster sizes $R_{n}<1$ has been observed, indicating an increase on the $\left(\mathrm{H}_{2} \mathrm{O}\right)_{n} \mathrm{H}^{+}$signals at these channels when co-adding $\mathrm{CO}$ and $\mathrm{NO}$ to water.

In order to understand the key factors affecting the softening process we introduce a term, the so-called normalized softening effect, to compare how the same quantity of co-dopant affects the $R_{n}$ value, assuming a linear dependence of $R_{n}$ on the amount of added co-dopant molecules. In our experiments the amount of co-dopant added to the helium droplets was quantified by the intensity of the dopant parent ion signal $(I)$ in the background mass spectra, which was measured by delaying the data acquisition gate to a time when

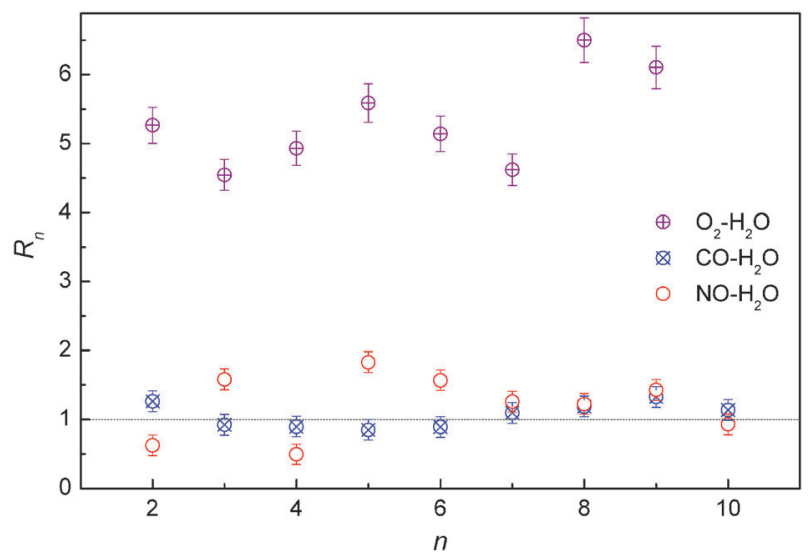

Fig. 5 Variation of $R_{n}$ with cluster size for the co-dopants $\mathrm{O}_{2}, \mathrm{CO}$ and NO. The NO plot is less reliable for $n>4$ because of the overlap of $\mathrm{NO}$ cluster ion signals with water cluster ion signals in the mass spectra, e.g., $(\mathrm{NO})_{3}\left(\mathrm{H}_{2} \mathrm{O}\right)_{n}{ }^{+}$coincides with $\left(\mathrm{H}_{2} \mathrm{O}\right)_{n+5}{ }^{+}(n=0,1$, $2 \ldots)$. The error margins shown are estimates based on the signalto-noise ratios for the various ion signals. 
Table 1 Comparison between the ionization energy, the dipole polarizability and the normalized softening effect for several co-dopants (au refers to atomic units)

\begin{tabular}{lrlc}
\hline & IE/eV & Dipole polarizability/au & Softening effect $(n=3)$ \\
\hline $\mathrm{Ar}$ & 15.76 & $10.75^{a}$ & 0 \\
$\mathrm{~N}_{2}$ & 15.58 & $11.57^{b}$ & 19.4 \\
$\mathrm{O}_{2}$ & 12.07 & $10.66^{c}$ & 121.8 \\
$\mathrm{CO}_{2}$ & 13.78 & $13.8^{d}$ & 252.6 \\
$\mathrm{C}_{6} \mathrm{D}_{6}$ & 9.25 & $67.48^{e}$ & 2546.8 \\
${ }^{a}$ & Ref. $18 .{ }^{b}$ Ref. $19 .{ }^{c}$ Ref. 20. ${ }^{d}$ Ref. 21. ${ }^{e}$ Ref. 22. \\
\hline
\end{tabular}

no helium droplets were present. In order to make a quantitative comparison between different co-dopants, we must account for differences in the ionization cross section $(\sigma)$ of the co-dopants at $100 \mathrm{eV}$ electron impact energy. It is also necessary to account for ion fragmentation at this electron impact energy, and thus the percentage of the parent ion signal in the mass spectrum $(P)$ is also incorporated into the model. In addition, $R_{n}$ values are obtained using bare water cluster spectra as the reference, and $R_{n}=1$ indicates no extra contribution from the co-dopant. Therefore we will use $R_{n}-1$ to describe the net softening effect of the co-dopants on water clusters. Consequently, the normalized softening effect for water clusters can be expressed as:

$$
S_{n}=\frac{R_{n}-1}{I \sigma P}
$$

A co-dopant exhibits a softening effect if $S_{n}$ is positive. As shown in Table 1, normalized softening effects of the selected nonpolar species follow the order $\mathrm{C}_{6} \mathrm{D}_{6}>\mathrm{CO}_{2}>\mathrm{O}_{2}>\mathrm{N}_{2}>\mathrm{Ar}$. We have not applied this softening parameter to $\mathrm{CO}$ and $\mathrm{NO}$, since they show a more complex softening response, and for some water cluster sizes they actually enhance the fragmentation process.

\section{Discussion}

$\left(\mathrm{H}_{2} \mathrm{O}\right)_{n}{ }^{+}$ions have a tendency to fragment because they are highly vibrationally excited when formed. It is critical to remove this energy rapidly in order to stabilize the parent ions, and the ability of co-dopants to carry away energy is therefore a key factor that affects the relative yield of the unprotonated and the protonated ions. The remaining energy in the vibrational degrees of freedom of water cluster ions after all co-dopant molecules have been removed also depends on the amount of excess energy delivered to the system from $\mathrm{He}^{+}$. Consequently, the findings of the current work might be explicable in terms of an 'energy-in' and 'energy-out' mechanism which determines the degree of fragmentation of water cluster ions.

The core-shell structure is important for the interpretation of experimental observations because it specifies the co-dopant molecules as the initial reactants with $\mathrm{He}^{+}$during the charge transfer reactions and thus determines the total energy delivered to the core-shell clusters. Consequently, the total energy to be dissipated for the formation of water parent ions is approximately $\mathrm{IE}_{\mathrm{X}}-\mathrm{IE}_{\mathrm{H}_{2} \mathrm{O}}+E_{\mathrm{i}}$, where $\mathrm{IE}_{\mathrm{X}}$ and $\mathrm{IE}_{\mathrm{H}_{2} \mathrm{O}}$ are ionization energies of the co-dopant $\mathrm{X}$ and water respectively, and $E_{\mathrm{i}}$ is the internal energy of 'hot' binary cluster ions generated in the primary charge transfer reactions between co-dopant and $\mathrm{He}^{+}$.

As well as the loss of energy through evaporation of helium atoms, energy can also be dissipated by evaporation of molecules from the core-shell clusters. The minimum energy that can be removed for each loss of a molecule is the binding energy between the neutral molecule and the charged particle, which is extremely difficult to estimate in this work because the binding energy varies with the number of the co-dopant molecules, the size of the water clusters, the geometry of the charged cluster and even the number of helium atoms surrounding the clusters. Also, the fragmentation of ionic clusters must occur before the reallocation of positive charge inside the cluster: otherwise the dissociation of the cluster will be governed by meta-stable decay of binary cluster ions, which will lead to water parent ions in preference to protonated water clusters. For example, in mass-selected metastable decay experiments on $\left[\mathrm{O}_{2}\left(\mathrm{H}_{2} \mathrm{O}\right)_{n}\right]^{+}$ions $(n=2-5),{ }^{23}$ Angel and Stace found that dissociation favoured the formation of unprotonated water cluster cations instead of the protonated ions. The general trend observed was that the $\mathrm{O}_{2}$-loss channel is about 3 times stronger than the channel that loses both $\mathrm{O}_{2}$ and $\mathrm{OH}$. However, as described in previous sections, the protonated water cluster ions are always the prominent feature in the present work, which clearly indicates that the initial location of the charge is not the same as the final thermodynamic limit, where the charge would be located on $\mathrm{O}_{2}$ because of its lower ionization energy. Although it is not possible to calculate the binding energy of the co-dopant to the cluster core, we do know that the dominant interaction between a positive charge and a non-polar neutral species is the charge-induced dipole interaction, which depends on the polarizability of the neutral species. Thus the ability to dissipate energy through this means can be related to the polarizability of the co-dopant.

We start with the simple case of argon, which shows no softening effect. Ar will react with $\mathrm{He}^{+}$first owing to the core-shell structure. The difference in ionization energy between $\mathrm{Ar}$ and $\mathrm{H}_{2} \mathrm{O}$ is $3.11 \mathrm{eV}\left(\mathrm{IE}_{\mathrm{Ar}}=15.58 \mathrm{eV}\right.$ and $\left.\mathrm{IE}_{\mathrm{H}_{2} \mathrm{O}}=12.65 \mathrm{eV}\right) .{ }^{24}$ The only way that the excess energy can be dissipated from the $\mathrm{H}_{2} \mathrm{O} / \mathrm{Ar}$ system without involving disruption of the water clusters is by the evaporation of $\mathrm{Ar}$ atoms, through which the amount equivalent to the dissociation energy will be removed. However, it appears that the quenching by this means alone is not able to exhibit a significant reduction in the fragmentation of water cluster ions relative to that of superfluid helium acting alone.

By way of contrast $\mathrm{O}_{2}$ and $\mathrm{N}_{2}$ show a substantial softening effect, with that of $\mathrm{O}_{2}$ being much the larger of the two. As $\mathrm{N}_{2}$ has a higher dipole polarizability than $\mathrm{O}_{2}$ (see Table 1), $\mathrm{N}_{2}$ will have a higher binding energy to the positively charged clusters than $\mathrm{O}_{2}$ and hence each $\mathrm{N}_{2}$ molecule is able to remove more energy when it leaves the clusters. However, since the softening effect is larger for $\mathrm{O}_{2}$, the key factor at work must be the difference in ionization energies (see Table 1) of $\mathrm{O}_{2}$ and $\mathrm{N}_{2}$ relative to water, i.e., more energy is delivered into the $\mathrm{H}_{2} \mathrm{O} / \mathrm{N}_{2}$ system than that of $\mathrm{H}_{2} \mathrm{O} / \mathrm{O}_{2}$ on ionization, with a difference of $\mathrm{IE}_{\mathrm{N}_{2}}-\mathrm{IE}_{\mathrm{O}_{2}}=3.51 \mathrm{eV}$. 
Compared with $\mathrm{O}_{2}, \mathrm{CO}_{2}$ has additional vibrational degrees of freedom and therefore its ability to carry away excess energy in the form of vibrational excitation is increased. In addition, $\mathrm{CO}_{2}$ has a higher dipole polarizability than $\mathrm{Ar}, \mathrm{O}_{2}$ and $\mathrm{N}_{2}$ so that it can remove more energy by evaporation. Consequently, these factors can explain why the softening effect offered by $\mathrm{CO}_{2}$ is significantly higher than $\mathrm{O}_{2}$, even though the ionization energy of $\mathrm{CO}_{2}$ is larger than that of $\mathrm{O}_{2}$. Unsurprisingly, $\mathrm{C}_{6} \mathrm{D}_{6}$ has the largest softening effect. It has a much lower ionization energy than water, it is expected to have the highest binding energy because of its large polarizability, and it has far more vibrational degrees of freedom than the other co-dopant molecules considered in this work.

NO and CO have markedly different effects on the fragmentation of water cluster ions compared with the other co-dopants. Some enhancement of the unprotonated ion signal relative to the protonated channel is observed for some water cluster sizes but more typically the fragmentation actually increases (see Fig. 3). In addition, although $\mathrm{CO}$ and NO have very different ionization energies (14.01 and $9.27 \mathrm{eV}$ respectively), ${ }^{24}$ their effect on water cluster ions is quite similar. This indicates that the 'energy-in and energy-out' mechanism is not the key factor deciding the outcome for these co-dopants. A major difference for these co-dopants is that both can serve as acceptors for $\mathrm{OH}$ radicals by formation of HONO and HOCO. This is unsurprising because nominal water cluster cations $\left(\mathrm{H}_{2} \mathrm{O}\right)_{n}{ }^{+}$form proton-transferred type clusters $\mathrm{H}^{+}\left(\mathrm{H}_{2} \mathrm{O}\right)_{n-1}(\mathrm{OH})$, with a dangling $\mathrm{OH}$ moiety on the surface. ${ }^{25}$ Both $\mathrm{CO}$ and $\mathrm{NO}$ can remove the $\mathrm{OH}$ and form stable reaction products. Experimentally this possibility has been demonstrated by Stace et al. in a mass spectrometric study of the gas phase dissociation reaction of $\left[\mathrm{NO}\left(\mathrm{H}_{2} \mathrm{O}\right)_{n}\right]^{+}$, in which HONO was identified as a product in addition to $\left(\mathrm{H}_{2} \mathrm{O}\right)_{n-1} \mathrm{H}^{+} .{ }^{13}$ We therefore postulate that secondary ion-molecule reactions leading to the formation of HONO and $\mathrm{HOCO}$ are responsible for the enhanced fragmentation of water cluster ions seen in the current helium droplet experiments, i.e.

$$
\begin{aligned}
{\left[\left(\mathrm{H}_{2} \mathrm{O}\right)_{n} \mathrm{NO}\right]^{+} } & \rightarrow\left(\mathrm{H}_{2} \mathrm{O}\right)_{n-1} \mathrm{H}^{+}+\mathrm{HONO} \\
{\left[\left(\mathrm{H}_{2} \mathrm{O}\right)_{n} \mathrm{CO}\right]^{+} } & \rightarrow\left(\mathrm{H}_{2} \mathrm{O}\right)_{n-1} \mathrm{H}^{+}+\mathrm{HOCO}
\end{aligned}
$$

\section{Conclusions}

In this work, superfluid helium droplets have been used to synthesize core-shell clusters with a water cluster in the core and a co-dopant as the shell. The fragmentation pattern of water cluster ions, i.e., $\left(\mathrm{H}_{2} \mathrm{O}\right)_{n}{ }^{+}$and $\left(\mathrm{H}_{2} \mathrm{O}\right)_{n} \mathrm{H}^{+}$ions, has been used as an indicator for the underlying ion-molecule reactions occurring following droplet ionization. The core-shell structure and, in particular, the identity of the co-dopant in the shell, can have a major effect on the fragmentation of the water cluster ions.

An 'energy-in and energy-out' mechanism has been proposed to account for the general softening effect on water cluster ion formation produced by the majority of co-dopants. In addition to the binding energy of the co-dopant to water molecules, which by itself is not sufficient to provide significant quenching, other key factors affecting the branching ratio between water cluster ion fragmentation and parent ion formation are the ionization energy of the co-dopant relative to water, and the number of internal vibrational degrees of freedom of the co-dopant.

However, for $\mathrm{CO}$ and $\mathrm{NO}$ co-dopants the behaviour is markedly different. $\mathrm{CO}$ and NO can act as acceptors for the $\mathrm{OH}$ radical produced by water cluster ion fragmentation by forming stable species such as HOCO and HONO, and the assistance of this process accounts for the enhanced formation of protonated water clusters seen for these co-dopants. A full understanding of the reaction mechanisms will require ab initio calculations of the reaction pathways and this is work currently in progress in our laboratory.

\section{References}

1 J. P. Toennies and A. F. Vilesov, Angew. Chem., Int. Ed., 2004, 43, 2622.

2 M. Hartmann, R. E. Miller, J. P. Toennies and A. F. Vilesov, Phys. Rev. Lett., 1995, 75, 1566.

3 S. Grebenev, J. P. Toennies and A. F. Vilesov, Science, 1998, 279 2083.

4 S. Grebenev, M. Hartmann, A. Lindinger, N. Pörtner, B. Sartakov, J. P. Toennies and A. F. Vilesov, Phys. B, 2001, 280, 65.

5 J. Higgins, W. E. Ernst, C. Callegari, J. Reho, K. K. Lehmann, G. Scoles and M. Gutowski, Phys. Rev. Lett., 1996, 77, 4532.

6 J. Higgins, C. Callegari, J. Reho, F. Stienkemeier, W. E. Ernst, K. K. Lehmann, M. Gutowski and G. Scoles, Science, 1996, 273, 629.

7 K. Nauta and R. E. Miller, Science, 1999, 283, 1895.

8 K. Nauta and R. E. Miller, Science, 2000, 287, 293.

9 M. Fárník and J. P. Toennies, J. Chem. Phys., 2005, 122, 014307.

10 S. Denifl, F. Zappa, I. Mähr, F. F. da Silva, A. Aleem, A. Mauracher, M. Probst, J. Urban, P. Mach, A. Bacher, O. Echt, T. D. Märk and P. Scheier, Angew. Chem., Int. Ed., 2009, 48, 8940.

11 Y. Ren and V. V. Kresin, J. Chem. Phys., 2008, 128, 074303.

12 W. K. Lewis, B. E. Applegate, J. Sztáray, B. Sztáray, T. Baer, R. J. Bemish and R. E. Miller, J. Am. Chem. Soc., 2004, 126, 11283.

13 A. J. Stace, J. F. Winkel, R. B. Lopez Martens and J. E. Upham, J. Phys. Chem., 1994, 98, 2012.

14 R. T. Jongma, Y. Huang, S. Shi and A. M. Wodtke, J. Phys. Chem. $A, 1998, \mathbf{1 0 2}, 8847$.

15 R. Fröchtenicht, M. Kaloudis, M. Koch and F. Huisken, J. Chem. Phys., 1996, 105, 6128.

16 S. Yang, S. Brereton, S. Nandhra, A. M. Ellis, B. Shang, L. Yuan and J. Yang, J. Chem. Phys., 2007, 127, 134303.

17 S. Yang, S. M. Brereton and A. M. Ellis, Rev. Sci. Instrum., 2005, 76, 104102.

18 N. K. Rahman, A. Rizzo and D. L. Yeager, Chem. Phys. Lett., 1990, 166, 565 .

19 H. J. A. Jensen, P. Jørgensen, T. Helgaker and J. Olsen, Chem. Phys. Lett., 1989, 162, 355.

20 A. C. Newell and R. C. Baird, J. Appl. Phys., 1965, 36, 3751.

21 A. Chrissanthopoulos, U. Hohm and U. Wachsmuth, J. Mol. Struct., 2000, 526, 323

22 S. P. Karna, G. B. Talapatra and P. N. Prassad, J. Chem. Phys., $1991,95,5873$.

23 L. Angel and A. J. Stace, J. Phys. Chem. A, 1999, 103, 2999.

24 NIST Chemistry WebBook, see http://webbook.nist.gov/chemistry/.

25 K. Mizuse, J. Kuo and A. Fujii, Chem. Sci., 2011, 2, 868. 